\title{
JUURNAL.RU
}

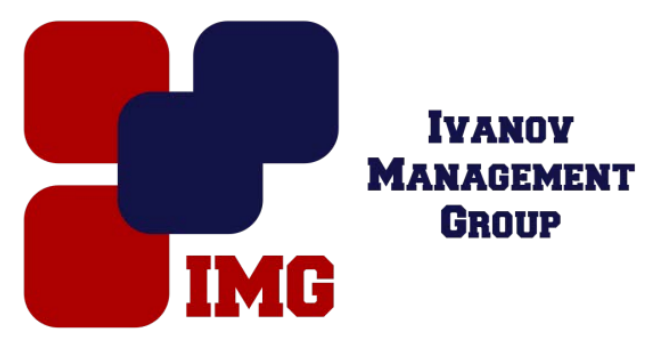

Иконникова Е.В., Стенько А.Г. ФГБУ ДПО «Центральная государственная медииинская академия» УДП РФ $O A O$ «Институт пластической хирургии и косметологии» Москва, Россия

doi: 10.18411/lj-28-02-2017-3-02

idsp 000001:lj-28-02-2017-3-02

\section{Гиперпигментация: современный взгляд на этиологию и методы коррекции}

\section{Аннотация}

В статье приводятся данные об основных этиологических факторах различных гиперпигментаций и современных методах коррекции. Приведены результаты клинических наблюдений применения наружных средств, содержащих в своем составе гликолевую кислоту, аскорбиновую кислоту и корень солодки как в виде монотерапии, так и в комбинации с лазерной терапией (1064 нм) у пациентов с гиперпигментациями различного происхождения, в том числе при мелазме и лентиго. Показана высокая эффективность и безопасность данных методов терапии, а также проведен их сравнительный анализ.

Ключевые слова: гиперпигментация; меланодермия; мелазма; лазер; лазерная терапия; гликолевая кислота; аскорбиновая кислота.

Меланин в организме человека, в первую очередь, отвечает за цвет кожных покровов, волос и цвет глаз. Он синтезируется меланоцитами посредством процесса, называемого меланогенез. Тем не менее, аномальное накопление меланина (меланиновый тип гиперпигментации) приводит к ряду дерматологических проблем, таких как солнечные лентиго (возрастные пятна), мелазма, эфелиды (веснушки).Эти состояния, а также посттравматическая гиперпигментация, в ряде случаев являясь косметическим дефектом, в значительной степени снижают качество жизни пациента. Хотя к нарушению пигментации могут приводить различные этиологические факторы, на сегодняшний день не было представлено различий в методе лечения этих расстройств. Таким образом, можно предположить, что в различные виды гиперпигментации кожи могут быть вовлечены общие патогенетические механизмы. 
В коже человека меланоциты располагаются на линии дермоэпидермального соединения, являющегося пограничной структурой между двумя основными отделами кожи -- эпидермисом и дермой. Меланоциты базального слоя эпидермиса производят различное количество и различные виды меланина (эумеланин/феомеланин), синтезирующиеся в органеллах, называемых меланосомы. Меланосомы перемещаются в отростки меланоцитов и передаются в соседние базальные кератиноциты. По мере дифференцировки кератиноцитов, меланосомы начинают деградировать в зависимости от типа кожи, что приводит либо к мелкодисперсным остаткам меланосом в светлой коже, либо меланосомы остаются неизмененными, вплоть до самых внешних слоев эпидермиса, в коже черного цвета.

Процесс биосинтеза меланина начинается с взаимодействия аминокислоты L-тирозина и фермента тирозиназы.Тирозиназа является ключевым ферментом меланогенеза в меланоцитах. Она действует в качестве катализатора для двух стадий меланогенеза -- гидроксилирования тирозина до 3,4дигидроксифенилаланина (DOPA) и окисления DOPA до DOPA-хинона.

DOPA-хинон превращается в содержащий индольное кольцо DOPA-хром, из которого при участии DOPA-хром-таутомеразы в присутствии ионов металлов, синтезируется дигидроксииндолилкарбоновая кислота (5,6-dihidroxyindole-2carboxylic acid, DHICA). Продукты окисления DHICA (ферментативного или неферментативного), полимеризуются, в результате чего образуется коричневый DHICA-меланин, содержащий от 100 до 1000 мономеров DHICA. DOPA-хром может также превращаться в 5,6-дигидроксииндол (5,6-dihidroxyindole, DHI). Продуктом окислительной полимеризации DHI является черный DHI-меланин.

DHI- и DHICA-меланины являются эумеланинами. Помимо этого, в меланоцитах синтезируются серосодержащие пигменты -- феомеланины (желтого, красного и коричневого цвета), предшественником которых является 5-Sцистеинил-DOPA (5-S-cysteinyldopa).Для синтеза феомеланиновых пигментов необходимо присутствие L-цистеина. В синтез эумеланинов вовлечены гены, ассоциированные с тирозиназой (белки TRP-1 иTRP-2). Тирозиназа, TRP-1 и TRP2-гены контролируются транскрипционным фактором (Microphtalmia-associated Transcription Factor -- MITF-M).

Также важными регуляторами меланогенеза являются такие производные пептида проопиомеланокортин (РОМС), как $\alpha$-меланоцитостимулирующий гормон $(\alpha \mathrm{MSH})$ и адренокортикотропный гормон (AСТH). $\alpha \mathrm{MSH}$ и АСТН были обнаружены в эпидермисе и дерме. Они производятся различными типами клеток, такими как кератиноциты, меланоциты, фибробласты и эндотелиальные клетки (нейроэндокринная система кожи).

Синтез меланина также регулируется внутренними факторами: медиаторами воспаления, факторами роста, нейромедиаторами, нейропептидами и гормонами (в частности, эстрогенами и глюкокортикоидами).

В коже меланоциты находятся в плотном контакте с соседними кератиноцитами. Большим количеством исследований подчеркивается роль 
кератиноцитов в контроле пигментации кожи. Например, кератиноциты способствуют транзиторному УФ-индуцированному меланогенезу (загар), секретируя паракринным путем многочисленные факторы роста, такие как aMSH, эндотелин-1 (ET-1), фактор стволовых клеток (SCF) и различные цитокины.Тем не менее, появляется все больше доказательств роли дермальных компонентов в регуляции пигментации.

В недавних исследованиях было продемонстрировано, что дермальные фибробласты оказывают регулирующую роль в пигментации посредством секреции растворимых факторов. Предполагается, что физиологические изменения фибробластов с течением времени, в частности в результате фотостарения, могут влиять на пигментирование кожи. Фотостарение кожи, индуцированное хроническим воздействием солнечных УФ-лучей связано с пигментными изменениями и образованием актинического кератоза (старческого лентиго), являющегося отличительной чертой фотоповрежденной возрастной кожи.

Также были проведены исследования о межклеточных взаимодействиях при формировании посттравматической гиперпигментации. Эпидермальная пигментация после повреждения кожных покровов возникает вследствие пролиферации меланоцитов, их миграции в рану, выработки меланина, а также передачи пигмента в ближайшие кератиноциты. Получены данные, которые показывают тесное взаимодействие меланоцитов с фибробластами, которые участвуют в совместной регуляции репарации кожных покровов. Это эпидермально-мезенхимальное взаимодействие может быть особенно актуально для изучения медленно заживающих ран, в котором несформировавшаяся базальная мембрана может обеспечивать прохождение паракриновых медиаторов между дермой и эпидермисом.

В качестве основных причин гиперпигментации традиционно рассматриваются генетические данные, хроническое воздействие ультрафиолетового (УФ) излучения, женские половые гормоны. Каждый из вышеуказанных факторов одновременно может вызывать разные нозологические нарушения пигментации, такие как пигментация, вызванная хроническим УФоблучением (фотостарение), пигментация вследствие приема оральных контрацептивов или поствоспалительной гиперпигментации. Существует возможность сосуществования различных видов гиперпигментации у одних и тех же пациентов, но их клинические характеристики будут различны.

Поствоспалительная гиперпигментация развивается в любом возрасте на месте воспаления, вызванного физической или химической травмой, раздражением кожи, вследствие контактного дерматита или различных дерматозов.

Пигментация, индуцированная хроническим УФ-облучением может сопровождаться характерными проявлениями фотостарения, такими как морщины, шероховатость, потеря упругости и тонуса кожи. 
По результатам гистологических исследований было отмечено сходство признаков мелазмы и солнечного эластоза, таких как дилатация капилляров кожи, частичное разрушение базальной мембраны с выпячиванием меланоцитов в дерму. Сходство микроскопических особенностей между кожей с хроническим воздействием УФ-излучения и мелазмой подчеркивают потенциальную роль кожного фотостарения и кумулятивного воздействия солнца в патогенезе меланодермии.

Генетическая предрасположенность считается одной из главных причин, влияющих на развитие гиперпигментации. Данные эпидемиологических исследований показывают, что существуют различия в появлении мелазмы у представителей разных рас, а также отмечают влияние отягощенного семейного анамнеза по данному типу пигментных расстройств.

Склонность к расстройствам пигментации, в частности к мелазме и поствоспалительной гиперпигментации, описывается во всех расовых и этнических группах, но чаще всего встречается у лиц с более темным типом кожи (III--V тип по Фитцпатрику), живущих в районах интенсивного УФ-излучения.

Женские половые гормоны способны влиять на возникновение гиперпигментации.Мелазма является распространенным физиологическим изменением кожи во время беременности. Также мелазма является побочным эффектом приема оральных контрацептивов. Эпидемиологические данные разных стран позволили диагностировать мелазму у 14,5--56\% беременных женщин и 11,3--46\% у женщин, использующих оральные контрацептивы.

Несмотря на недавний прогресс в понимании патогенеза нарушений пигментации, связь между появлением гиперпигментации и каждым этиологическим фактором определена на сегодняшний день лишь частично. До сих пор остается неясным, какие факторы играют главную роль в запуске патогенетического механизма. Кроме того, не каждый пациент с гиперпигментацией имеет сходные клинические и гистологические признаки. Предполагается, что развитие гиперпигментации может включать в себя различные этиологические и патогенетические факторы.

Стандартный план лечения обычно включает удаление провоцирующих факторов, использование фотозащиты и проведение активной редукции пигмента с помощью средств для местного применения или посредством физических методов.

Из местных осветляющих агентов наиболее широко применяются гидрохинон, азелаиновая кислота, ретиноиды, койевая кислота, гликолевая кислота, аскорбиновая кислота, производные лакрицы (солодки), производные сои, арбутин, ниацинамид, транексамовая кислота.

Из физических методов лечения наиболее широко применяется лазерная терапия. Лечение гиперпигментации с применением лазерных и световых источников основано на наблюдениях за биологическими свойствами пигмента в эпидермисе и дерме. 
Согласно теории селективного фототермолиза, селективность лазера по отношению к коже обусловлена тем, что световые волны разной длины поглощаются разными хромофорами кожи. Это позволяет «селективно» уничтожать структуры-мишени без повреждения окружающих тканей. Тремя основными хромофорами кожи являются вода, гемоглобин и меланин.

Наиболее популярными из ныне используемых электрооптических лазеров являются: рубиновый лазер (694 нм), александритный лазер (755 нм), Nd:YAG лазер (1064 нм), Nd:YAG лазер с удвоенной частотой (532 нм).

Селективный фототермолиз с помощью разных типов лазеров является весьма действенным для эпидермальных и дермальных пигментных поражений. Также для этих же целей часто используют и IPL-системы (Intensive Pulse Light), что подразумевает применение высокоинтенсивного импульсного света.

Более длинные волны проникают глубже и могут быть нацелены на пигмент, расположенный в дерме, но меланин лучше поглощает волны более короткой длины. Испытания многих световых и лазерных источников проводили с учетом этих данных. Однако, данный метод лечения является довольно сложной задачей из-за высокого риска повреждения окружающих тканей, а также тем, что может приводить к длительной и стойкой поствоспалительной гиперпигментации. К тому же терапия дермальной формы мелазмы и поствоспалительной пигментации представляет некоторые сложности в связи с тем, что влияние этиологических факторов возникновения данных патологических состояний может сохраняться и приводить к рецидивам.

В настоящее время появляются все новые исследования на тему сочетанного применения различных видов лазерной терапии между собой и в комбинации с другими методами лечения.

В большинстве случаев гиперпигментации, лазеры следует применять в качестве терапевтических средств 2-й и 3-й линии. Терапия с помощью лазеров может характеризоваться непредсказуемым ответом, частыми рецидивами и высокой степенью риска как поствоспалительной гипер- так и гипопигментации. Правильное консультирование пациента в отношении побочных эффектов и его ожиданий вместе с тестовым применением лазера всегда должны проводиться до любой лазерной процедуры.

\section{Материалы и методы.}

В клинических условиях под нашим наблюдением находилось 16 пациентов, из них $13(81,2 \%)$ женщин и $3(18,7 \%)$ мужчин с очагами гиперпигментации (мелазма) в возрасте от 27 до 58 лет - средний возраст 35,8 $\pm 5,2$ лет. Преимущественно процесс локализовался на коже лица, в области декольте и тыльной поверхности кистей - 12 (75\%) пациентов, у 4 (25\%) на коже туловища или конечностей. У 8 (50\%) пациентов отмечалась взаимосвязь образования гиперпигментации с ультрафиолетовым облучением (солнечная инсоляция, посещение соляриев) - солнечное лентиго, у 4 (25\%) пациентов появление гиперпигментации было связано с разрешением воспалительного кожного процесса (красный плоский лишай, атопический дерматит, токсидермия) - 
поствоспалительная гиперпигментация. $\mathrm{У} 2$ (12,5\%) пациентов причиной образования гиперпигментации были лазерные воздействия (шлифовка, фракционное лазерное омоложение кожи, удаление сосудистых или пигментных элементов) с последующим применением неадекватной фотозащиты (нерегулярное использование фотозащитных средств, низкая степень фотозащитных средств - $\mathrm{SPF}<20) .2$ (12,5\%) пациента образование гиперпигментации связывали с наружным применением косметологических средств (кортикостероиды, ретиноиды).

У всех пациентов отмечалось очаговое отложение меланина в поверхностных эпидермальных слоях кожи, что подтверждалось дерматоскопическим исследованием: диффузное равномерное распределение пигмента в очагах (дерматоскоп Heine Delta 20, Германия).

Критериями включения стали: наличие участков эпидермальной гиперпигментации кожи, обусловленной ультрафиолетовым излучением, лазерным воздействием, применением наружных препаратов, поствоспалительная гиперпигментация; фенотип кожи II, III или IV (в соответствии с классификацией Фицпатрика); добровольное информированное согласие.

\section{Результаты и их обсуждение.}

Целью исследования стала оценка эффективности и безопасности комбинированной терапии гиперпигментации неодимовым лазером (1064 нм) и топическим средством, содержащимгликолевую кислоту, корень солодки и аскорбиновую кислоту.

Неодимовый лазер (1064 нм) широко применяется для терапии различной кожной патологии, в том числе и гиперпигментаций.Он способен испускать световые волны с длиной 1064 нм, что соответствует ближнему инфракрасному спектру. Модулятор добротности - Q-Switch - позволяет формировать световые импульсы очень короткой протяженности (до 6 нс) при большой мощности световой энергии, это позволяет воздействовать на ткани организма с минимальным повреждающим эффектом.Во время лазерной вспышки происходит фотокавитация пигмента, находящегося в эпидермальных и дермальных слоях кожи, что делает доступной утилизацию частиц пигмента макрофагальной системой.

Гликолевая кислота, имея самую маленькую из АНА молекулярную массу, обладает наилучшей проникающей способностью. В небольших концентрациях она ослабляет сцепление корнеоцитов в нижней части рогового слоя, ускоряя тем самым обновление эпидермиса. Кроме отшелушивающего действия, гликолевая кислота стимулирует синтез коллагеновых волокон и межклеточного вещества. Механизм этого действия до конца не ясен. Возможно, он связан со стимуляцией фибробластов за счет травматизации кожи. В результате действия гликолевой кислоты роговой слой становится тоньше, а дерма утолщается. Некоторые исследования указывают на антиоксидантное и противовоспалительное действие. За счет сочетания отшелушивающего и пролиферативного эффекта применение гликолевой кислоты способствует выравниванию текстуры и цвета кожи. 
Аскорбиновая кислота, также известная как витамин С, обладает антиоксидантными свойствами и способностью тормозить меланогенез, ингибируя тирозиназу (связывая медь в активном центре тирозиназы). Являясь сильным восстановителем, аскорбиновая кислота способна восстановить ДОФАхром до ДОФА-хинона. Аскорбиновая кислота часто используется в составе комбинированной терапии. В целом, эта молекула быстро окисляется, является крайне нестабильной и при использовании ее в качестве монотерапии дает слабые результаты. Вследствие этого, как правило, ее сочетают с другими действующими веществами для повышения терапевтической эффективности.

Помимо этого, в состав наружного средства входил другой ингибитор тирозиназы - экстракт корня солодки. Данный экстракт обладает противовоспалительными свойствами и содержит вещество глабридин, который способен ингибировать тирозиназу в культуре клеток меланоцитов человека, не влияя при этом на синтез ДНК и РНК.

Результаты многочисленных исследований показывают, что для достижения выраженного и стабильного результата необходимо воздействовать на все звенья патогенеза патологического процесса. Сочетание в одном препарате нескольких ингредиентов с однонаправленным действием позволяет снизить концентрацию агрессивных компонентов и ведет к усилению желаемого результата и уменьшению побочных эффектов.

Все пациенты в зависимости от проводимой терапии были распределены в случайном порядке на 2 группы в зависимости от проводимого терапевтического комплекса.Первая группа (8 человек) в течение 3 месяцев наносили топическое средство, содержащее в своем составе гликолевую кислоту, корень солодки и аскорбиновую кислоту 2 раза в день (утро/вечер) непосредственно на очаги гиперпигментации. Лазерная терапия у данной группы не применялась.

Второй группе пациентов (8 человек) проводилась комбинированная терапия - применение топического средства по аналогичной схеме в сочетании с лазерной терапией неодимовым лазером (1064 нм). Всего было проведено 3 процедуры лазерной терапии с интервалом 1 месяц. Параметры лазерного излучения не изменялись в течение исследования и составляли: пятно $10 \mathrm{~mm}$, величина флюенса 8-10 Дж/см2, частота 7-10 Гц, количество проходов от 1 до 8 до появления легкой эритемы.

Выраженность пигментации оценивали до, через 1 мес и после завершения курса терапии (3 мес). Итоговый контроль был проведен через месяц после прекращения курса терапии в обеих группах.

Контроль эффективности применения терапии проводился через каждые 4 недели использования топического средства (первая группа) и через каждые 4 недели после первого сеанса лазерной терапии (всего 3 визита).Итоговый контроль эффективности применения терапии был проведен через месяц после прекращения курса терапии в обеих группах.

Был проведен сравнительный анализ монотерапии гиперпигментации топическим средством, содержащимгликолевую кислоту, корень солодки и 
аскорбиновую кислоту и сочетанной терапии с применением неодимового лазера (1064 нм) и топического средства.

Так уже на втором визите в обеих группах (первая группа - 31,2\%, вторая группа - 50\%) пациентов отмечалось улучшение состояния с точки зрения выраженности пигментации. Через месяц после окончания курса терапии полное исчезновение или значительное уменьшение пигментации отмечалось у $75 \%$ (первая группа) и у $87,5 \%$ (вторая группа).

Таблица 1.

Сводная таблица влияния проведенных методов терапии на очаги гиперпигментачии.

\begin{tabular}{|c|c|c|c|c|}
\hline $\begin{array}{c}\text { Исследуемый } \\
\text { признак }\end{array}$ & $\begin{array}{c}\text { Первая группа } \\
4 \text { недели (2 } \\
\text { визит) } \\
\text { (абс.\%) }\end{array}$ & $\begin{array}{c}\text { Первая группа } \\
16 \text { недель }(4 \\
\text { визит) } \\
\text { (абс./\%) }\end{array}$ & $\begin{array}{c}\text { Вторая группа } \\
\text { недели }(2 \\
\text { визит) } \\
\text { (абс./\%) }\end{array}$ & $\begin{array}{c}\text { Вторая группа } \\
16 \text { недель }(4 \\
\text { визит) } \\
\text { (абс./\%) }\end{array}$ \\
\hline $\begin{array}{c}\text { Общее } \\
\text { улучшение } \\
\text { состояния с } \\
\begin{array}{c}\text { точки зрения } \\
\text { пигментации }\end{array}\end{array}$ & $5(31,2 \%)$ & $12(75 \%)$ & $8(50 \%)$ & $14(87,5) \%$ \\
\hline $\begin{array}{c}\text { Побочные } \\
\text { эффекты } \\
\text { (эритема, } \\
\text { чувство жжения) }\end{array}$ & $1(6,2 \%)$ & $1(6,2 \%)$ & $0(0 \%)$ & $0(0 \%)$ \\
\hline
\end{tabular}

Побочные эффекты в виде эритемы и чувства жжения, возникающие непосредственно после нанесения топического средства, отмечались у одного пациента из первой группы (6,2\%), данные явления носили проходящий характер и не требовали дополнительной коррекции.Во второй группе переносимость как топической, так и лазерной терапии была высокой, побочных эффектов не наблюдалось.

Общая терапевтическая эффективность применения обеих видов терапии в коррекции гиперпигментации оценивалась по модифицированной шкале IGA(оценка общей интенсивности гиперпигментации по пятибалльной шкале (от 0 - чистая кожа, до 5 - очень интенсивная пигментация).Параметры пациентов в обеих группах после проведенного курса терапии показали значительное улучшение по шкале IGA и были сопоставлены друг с другом. До проведения монотерапии топическим средством (первая группа) параметр IGA составлял $1,8 \pm$ 0,4 ; после проведенной терапии значения IGA стали ниже на 27,7\% и достигли 1,3 $\pm 0,1$. До проведения комбинированной терапии (неодимовый лазер (1064 нм) и топическое средство) параметр IGA составлял $1,7 \pm 0,3$; после проведенной терапии значения IGA стали ниже на $35,2 \%$ и достигли $1,1 \pm 0,3$. По данным дерматоскопии и фотографирования была подтверждена клиническая эффективность обоих методов терапии.

Поскольку очаги пигментации, особенно локализующиеся на открытых участках кожи, в значительной степени снижают качество жизни, была проведена оценка психосоматического статуса пациентов до и после лечения на основании динамики дерматологического индекса качества жизни (ДИКЖ). До лечения 


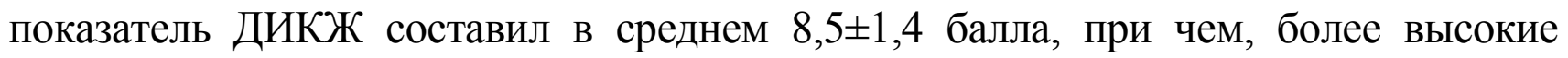
значения отмечались у пациентов с локализацией процесса на коже лица $-11,2 \pm 1,3$ балла, что свидетельствует о выраженном неблагоприятном влиянии данного косметического дефекта на качество жизни пациентов. После применения монотерапии топическим средством индекс ДИКЖ в среднем улучшился на 71,7\% и составил - 2,4 $\pm 0,5$ балла. После применения комбинированной терапии (неодимовый лазер (1064 нм) и топическое средство) индекс ДИКЖ в среднем улучшился на $81,1 \%$ и составил - $1,6 \pm 0,5$ балла.

\section{Заключение.}

Таким образом, по оценке самими пациентами эффективности и комфортности проводимого лечения, использование обеих видов терапии является высокоэффективным и безопасным методом эстетической коррекции гиперпигментации, однако комбинированная терапия показала значительно более высокую терапевтическую эффективность, что было подтверждено результатами исследования. 


\section{Литература}

1. Потекаев Н.Н., Круглова Л.С.Гиперпигментация: причины возникновения и методы коррекции. Клиническая дерматология и венерология. 2012; 10(6): 65--70.

2. Круглова Л.С., Стенько А.Г.,Стрелкович Т.И. Этиология, патогенез, классификация и современные возможности лечения неопухолевых гиперпигментаций кожи. Пластическая хирургия и косметология. 2014 (1): 105-110.

3. Олисова О. Ю., Андреева Е. В. Еще раз о проблеме гиперпигментации. // Российский журнал кожных и венерических болезней 2014, 2 (17): 20--24.

4. Круглова Л.С., Стенько А.Г., Стрелкович Т.И. Этиология, патогенез, классификация и современные возможности лечения неопухолевых гиперпигментаций кожи. Пластическая хирургия и косметология. 2014 (1): 105-110.

5. Потекаев Н.Н., Круглова Л.С.Лазер в дерматологии и косметологии. Москва: МДВ, 2012. - 280c.

6. Бауманн, Л. Косметическая дерматология: принципы и практика. Пер. с англ. под ред. Н. Н. Потекаева. Москва: Медпресс-информ, 2012. - 688 с.

7. Lee A.Y. Recent progress in melasma pathogenesis. Pigment Cell Melanoma Res.2015; 28(6): 648--60. doi: 10.1111/pcmr.12404.

8. Duval C., CohenC., ChagnoleauC., Flouret V., Bourreau E., F. Slominski. Key regulatory role of dermal fibroblasts in pigmentation as demonstrated using a reconstructed skin model: impact of photo-aging. PLoS One. 2014, 9(12): e114182.

9. Handel, A.C., Miot, L.D., Miot, H.A. Melasma: a clinical and epidemiological review. // Anais Brasileiros De Dermatologia, 2014ª 89, 771-782.

10. Kim, JE, Chang, SE, Yeo UC, Haw S, Kim IH. Histopathological study of the treatment of melasma lesions using a low-fluence Q-switched 1064-nm neodymium:yttrium-aluminiumgarnet laser.// Clin. Exp. Dermatol. 2013 a. 38, 167-171.

11. Cardinali G, Kovacs D, Picardo M. Mechanisms underlying post-inflammatory hyperpigmentation: lessons from solar lentigo. // Ann Dermatol Venereol. 2012,139, 3:96101 doi: 10.1016/S0151-9638(12)70127-8.

12. Gilchrest B.A. A review of skin ageing and its medical therapy. Br. J. Dermatol. 1996, 135, 867-875.

13. Vashi N.A., Kundu R.V. Facial hyperpigmentation: causes and treatment. Br. J. Dermatol. 2013, 169(3):41-56.

14. Paine C, Sharlow E, Liebel F,Eisinger M, Shapiro S, Seiberg M. An alternative approach to depigmentation by soybean extracts via inhibition of the PAR-2 pathway. J. Invest. Dermatol. 2001; 116(4):587-95.

15. Bang S.H., Han S.J., Kim D.H.Hydrolysis of arbutin to hydroquinone by human skin bacteria and its effect on antioxidant activity.J. Cosmet. Dermatol. 2008; 7(3): 189--93.doi: 10.1111/i.1473-2165.2008.00387.x.

16. Ibrahim Z.A., Gheida S.F., El Maghraby G.M., Farag Z.E. Evaluation of the efficacy and safety of combinations of hydroquinone, glycolic acid, and hyaluronic acid in the treatment of melasma. J. Cosmet. Dermatol. 2015; 14(2): 113--23.

17. Chaudhary S., Dayal S. Efficacy of combination of glycolic acid peeling with topical regimen in treatment of melasma. J. Drugs. Dermatol. 2013; 12(10): 1149--53.

18. Patil U.A., Dhami L.D.Overview of lasers. Indian J. Plast. Surg. 2008; 41(Suppl): S101--13.

19. Negishi K., Tanaka S., Tobita S. Prospective, randomized, evaluator-blinded study of the long pulse 532-nm KTP laser alone or in combination with the long pulse 1064-nm Nd: YAG laser on facial rejuvenation in Asian skin. Lasers Surg. Med. 2016; 48(9): 844--51.doi: 10.1002/lsm.22582. 